\title{
ADDRESSING MYTHS OF OUR MEDICAL COMMUNITY REGARDING RESEARCH
}

\author{
Iftikhar Ahmad \\ Department of Community Medicine, Gomal Medical College, D.I.Khan, Pakistan
}

Writing the first research article is always considered a difficult task. With experience, the difficulty level decreases but still it's not less than a nightmare for most of our medical community. Faculty, consultants and students are generally found struggling with their research projects. They are engaged in research, including basic science research, public health/ social science research, medical education research or clinical research. Research is conducted for one or more of the three reasons including identifying magnitude of the problem, cause of the problem or actual solution of the problem.

Research logically is a systematic, data-based, process of solving the problems of a specified (identified, defined) population. Research, operationally has four predefined and predetermined steps of topic selection \& formulation (TS \& F), data collection (DC), data analysis (DA) and report writing (thesis, dissertation, articles). TS\& F forms the basis of research proposal, whereas thesis consists of all the four steps. Writing research article is based on IMRAD style of introduction, methodology, results and discussion.

Topic once selected is formulated into a research proposal by conducting a mini research on the topic to make a framework of variables interconnected logically. 'Marwat's logical trajectory of research process, ${ }^{1-4}$ devised by one of our colleagues is an eight-step, skill-based approach which makes very easy for researchers to conduct their projects. It helps them not to lose their track. Proposal consists of introduction and methodology sections. The introduction means explaining how the present re- search is a solution to the research problem of our interest, whereas methodology is the how, when, who, where of the topic, consisting of all plans \& tools of the forthcoming steps of the full project/ thesis/ dissertation. Besides operational definitions, significance and rationale need to be mentioned in proposal which is now ready for approval by those concerned.

Common misconceptions and myths regarding research among our medical community, responsible for their general lack of motivation towards doing research are listed below along with their demystification.

Myth1: Research is boring and difficult. Better identify someone engaged in research to include me in the list of authors.

The answer is that research is neither boring nor difficult. Like all other subjects, it needs commitment to learn terminologies of research and have a knowhow of the research language. Gradually one starts developing a firm grip in the research and things start becoming interesting and fascinating.

Myth2: For research paper writing some knowhow of research is all that is needed.

Research methodology is knowledge, attitude and a skill. Like other skills, it needs to be learned and mastered. Competency in any skill can only be achieved if an expert research supervisor is available all the time to coach a learner on the analogy of sports. Superficial knowledge of research methodology is not sufficient rather it needs to be properly digested and be made part of our flesh and bones.

KEY WORDS: Knowledge; Attitude; Research.

Cite as: Ahmad I. Addressing myths of our medical community regarding research [editorial]. Gomal J Med Sci 2021 Apr-Jun; 19(2):45-6. https://doi.org/10.46903/gjms/19.02.955

\section{Corresponding Author:}

Prof. Dr. Iftikhar Ahmad

Department of Community Medicine

Gomal Medical College, D.I.Khan, Pakistan

E-mail: iftikharahmadgandapur66@gmail.com

$\begin{array}{ll}\text { Date Submitted: } & 24-12-2020 \\ \text { Date Revised: } & 19-03-2021 \\ \text { Date Accepted: } & 27-03-2021\end{array}$

Myth 3: We have sufficient number of research teachers in the field of medicine.

It's not correct. We do have a lot of highly qualified people having, FCPS, MS, MPhil and PhD degrees. Some are purely research degrees. Unfortunately majority of them don't have the required ability to coach their juniors in research methodology. They themselves are not fully trained; rather they did their thesis to fulfill the criteria for their respective qualifica- 
tion. They lack that particular coaching skill which is needed by their juniors to become good researchers.

Myth 4: There is no need to spend hours learning research.

No. Research cannot be taken as for granted. Medical community must give as much respect to doing research as their respective specialties. They will have to take pains to learn and do research. Research is equally important in promoting their careers as their own fields of practice. The requisite subjects for learning research include; their respective subject/ specialty, epidemiology, biostatistics and research methodology (art of writing research). Many a time workshops about the above mentioned subjects are taken as wastage of time and the skill to write a good research article is demanded as a short cut, which is wrong.

Myth 5: Research is done for the sample and on the sample.

This is not correct. Research is directed always to the population \& not for sample. It solves the problem for a specified population through a sample. Data collection at population level (census) is ideal but not feasible due to resource constraints. Hence we opt for representative sampling from our population of interest, which is feasible but of course not ideal. Practically most studies start with a sample and end at a sample. There is no mention of defined population, appropriate sampling, proper data collection, estimation of parameter or hypothesis testing, which is altogether anything but not research. ${ }^{1-4}$
In short, medical community should give research its due respect in terms of inputs; ample understanding of epidemiology and biostatistics and research methodology, invest time in learning from research experts and developing the attitude of a genuine researcher.

\section{REFERENCES}

1. Ain N, Khan S, Marwat M, Khan N, Ahmad I, Ramzan F, et al. Frequency, distribution and determinants of hypertension in adult stroke population of D.I.Khan Division, Pakistan. Gomal J Med Sci 2019 Jul-Sep; 17 (3):81-9. https://doi. org/10.46903/gjms/17.03.2076

2. Marwat M, Ahmad I, Ashiq F, Ali S, Zamir S, Rehman MU, et al. Frequency, distribution and determinants of diabetes mellitus in adult acute coronary syndrome population of D.I.Khan Division, Pakistan. Gomal J Med Sci 2019 OctDec; 17 (4):131-43. https://doi.org/10.46903/ gjms/17.04.2106

3. Shah S, Basharat A, Shah M, Marwat M, Billah M, Ali SM. Frequency, distribution and presentation of hypocalcemia in B-thalassemia major. Gomal J Med Sci 2018 Jan-Mar; 16(1): 2-8. https://doi. org/10.46903/gjms/16.01.1446

4. Shah HU, Gul H, Khan R, Marwat M. Urethrocutaneous fistula following Snodgrass versus two stage Aivar Bracka repair of distal penile hypospadias in male children: a randomized control trial. Gomal J Med Sci 2018 Apr-Jun; 16 (2): 54-8. https://doi.org/10.46903/gjms/16.02.1284

CONFLICT OF INTEREST
Authors declare no conflict of interest.
GRANT SUPPORT AND FINANCIAL DISCLOSURE
None declared.

(C) $(1) \Theta$

Copyright $\odot$ 2021. Iftikhar Ahmad. This is an Open Access article distributed under the terms of the Creative Commons Attribution-NonCommercial 4.0 International License, which permits unrestricted use, distribution \& reproduction in any medium provided that original work is cited properly. 